\title{
Eremophilane Sesquiterpenes from Ligularia macrophylla
}

Qi Wang, ${ }^{\dagger}$ Qing Mu, ${ }^{\dagger}$ Makio Shibano, ${ }^{\ddagger}$ Susan L. Morris-Natschke, ${ }^{\ddagger}$ Kuo-Hsiung Lee, ${ }^{*}$ ${ }^{\ddagger}$ and Dao-Feng Chen*, ${ }^{\dagger}$

Department of Pharmacognosy, School of Pharmacy, Fudan University, Shanghai 200032, People's Republic of China, and Natural Products Research Laboratories, School of Pharmacy, University of North Carolina, Chapel Hill, North Carolina 27599

\section{Supporting Information}

S1. ${ }^{1} \mathrm{H}$ NMR spectrum $\left(400 \mathrm{MHz}, \mathrm{CDCl}_{3}\right)$ of the new compound $\mathbf{1}$.

S2. ${ }^{13} \mathrm{C}$ NMR spectrum $\left(100 \mathrm{MHz}, \mathrm{CDCl}_{3}\right)$ of the new compound $\mathbf{1}$.

S3. HMBC spectrum of the new compound 1.

S4. ROESY spectrum of the new compound 1.

S5. ${ }^{1} \mathrm{H}$ NMR spectrum $400 \mathrm{MHz}, \mathrm{CDCl}_{3}$ ) of the new compound 2.

S6. ${ }^{13} \mathrm{C}$ NMR spectrum $\left(100 \mathrm{MHz}, \mathrm{CDCl}_{3}\right)$ of the new compound 2.

S7. ROESY spectrum of the new compound 2.

S8. ${ }^{1} \mathrm{H}$ NMR spectrum $\left(400 \mathrm{MHz}, \mathrm{CDCl}_{3}\right)$ of the new compound 3.

S9. ${ }^{13} \mathrm{C}$ NMR spectrum $\left(100 \mathrm{MHz}, \mathrm{CDCl}_{3}\right)$ of the new compound 3.

S10. HMBC spectrum of the new compound 3.

S11. ${ }^{1} \mathrm{H}$ NMR spectrum $\left(400 \mathrm{MHz}, \mathrm{CDCl}_{3}\right)$ of the new compound 4 .

S12. ${ }^{13} \mathrm{C}$ NMR spectrum $\left(100 \mathrm{MHz}, \mathrm{CDCl}_{3}\right)$ of the new compound 4.

S13. HMBC spectrum of the new compound 4.

S14. ROESY spectrum of the new compound 4.

\footnotetext{
* To whom correspondence should be addressed. Tel: +86-21-54237453. Fax: +86-21-64170921. E-mail: dfchen@shmu.edu.cn (D.F.C.) or khlee@unc.edu (K. H. L.).

${ }^{\dagger}$ School of Pharmacy, Fudan University

${ }^{\ddagger}$ Natural Products Research Laboratories, School of Pharmacy, University of North Carolina at Chapel Hill.
} 
S1. ${ }^{1} \mathrm{H}$ NMR spectrum (400MHz, $\mathrm{CDCl}_{3}$ ) of the new compound $\mathbf{1}$.

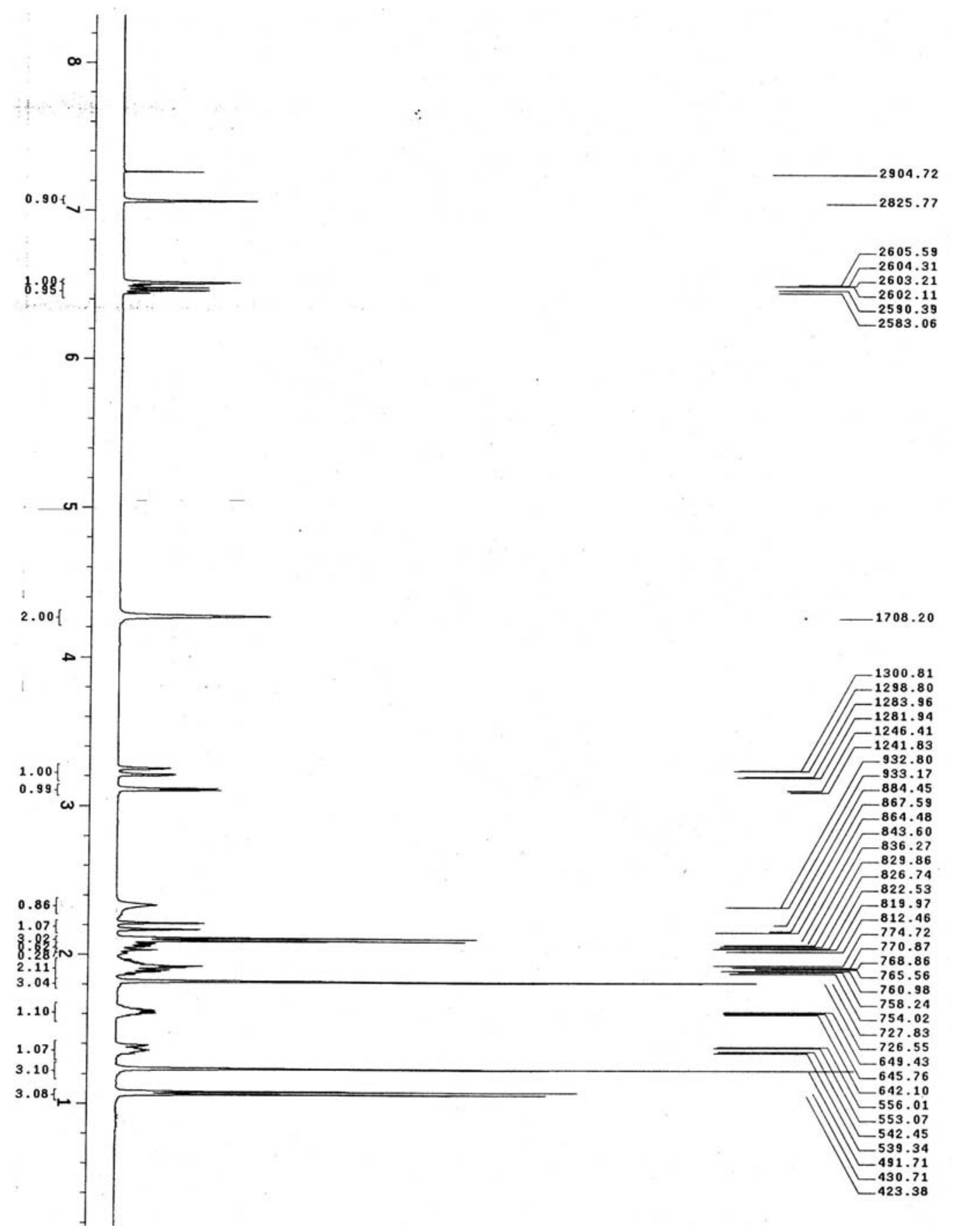


S2. ${ }^{13} \mathrm{C}$ NMR spectrum $\left(100 \mathrm{MHz}, \mathrm{CDCl}_{3}\right)$ of the new compound $\mathbf{1}$.
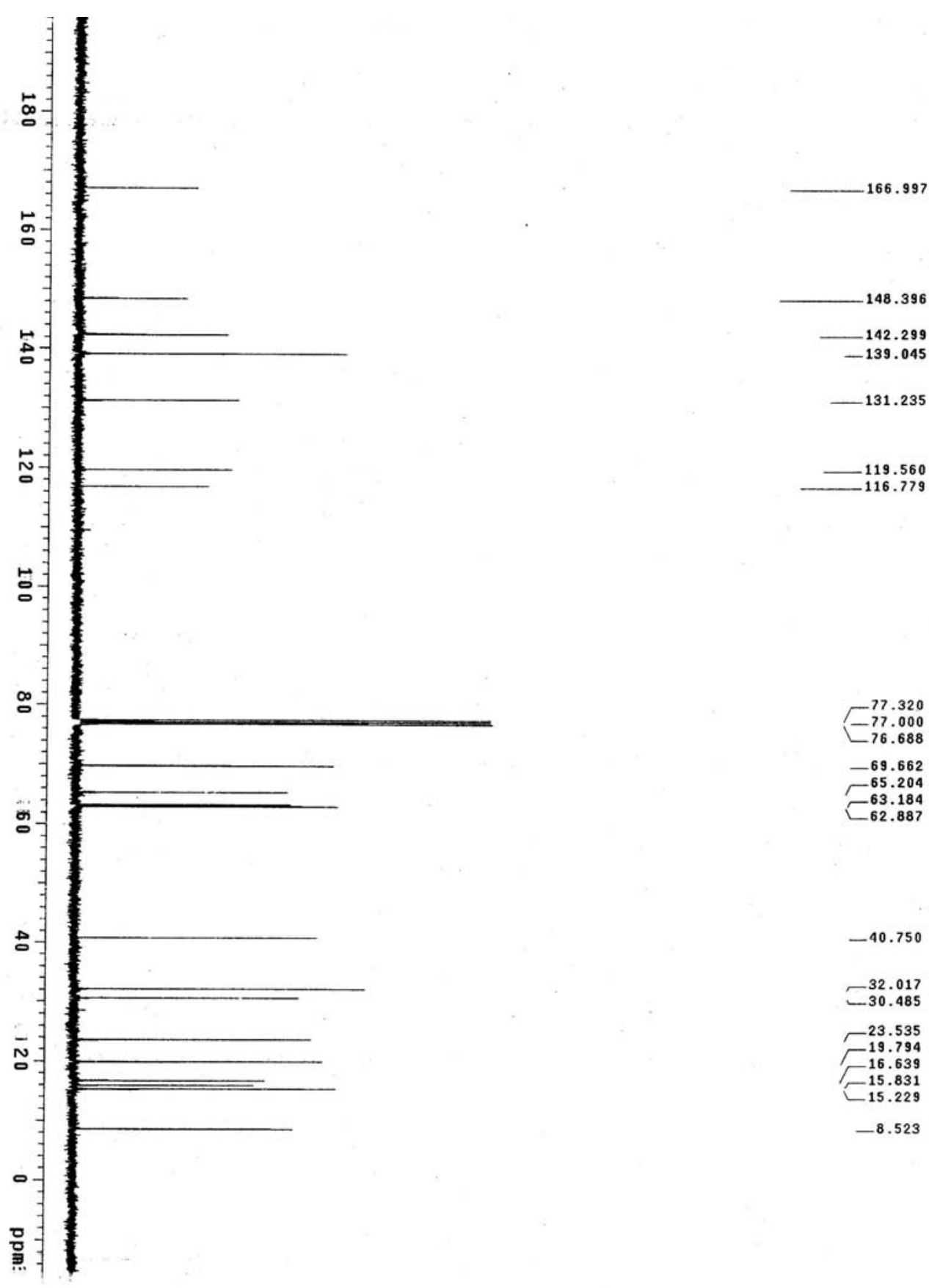

$-40.750$

-32.017
$-\quad 30.485$

$-23.535$

$-19.794$

$-16.639$

$-15.831$

$-8.523$ 
S3. HMBC spectrum of the new compound $\mathbf{1}$.

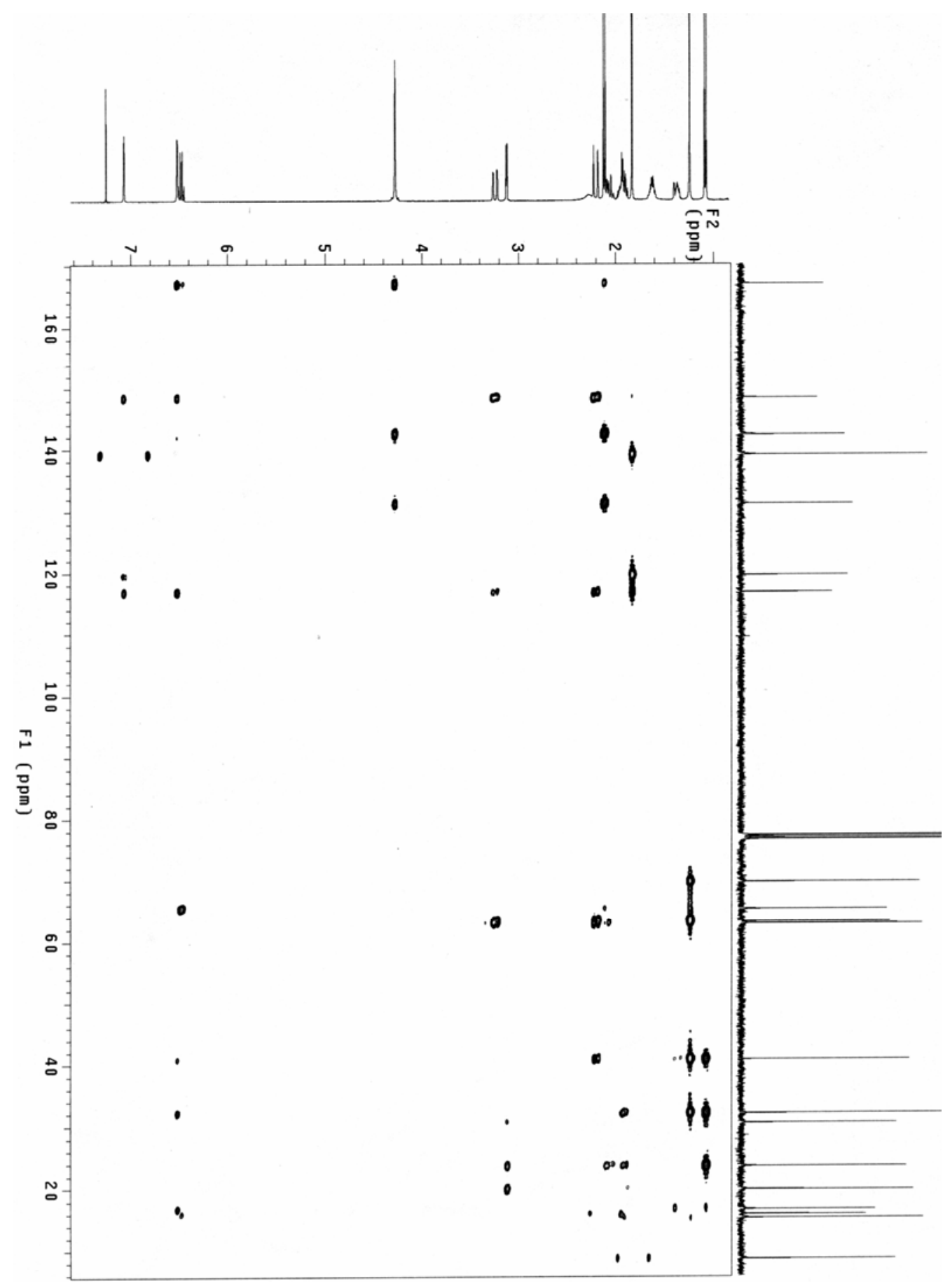


S4. ROESY spectrum of the new compound $\mathbf{1}$.

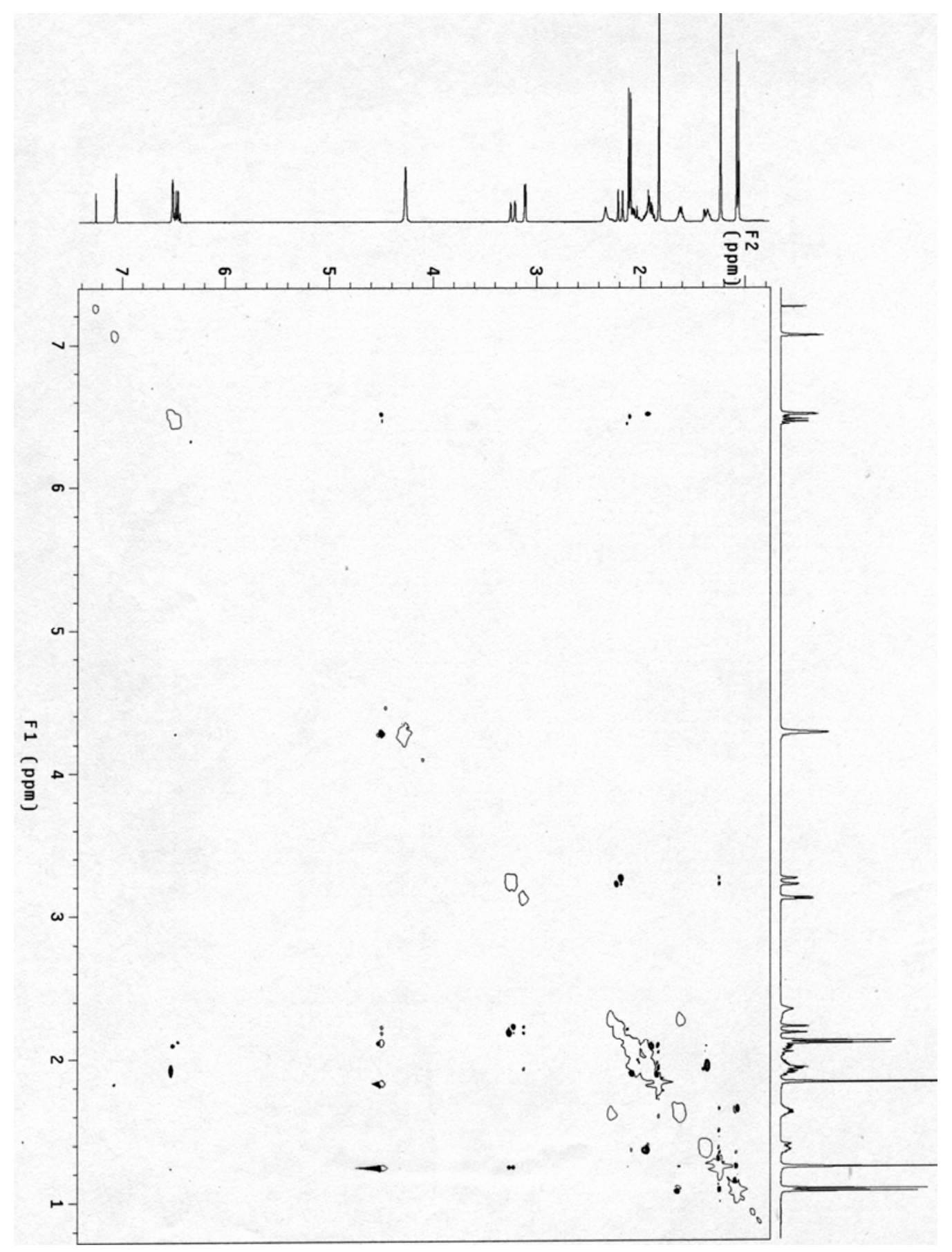


S5. ${ }^{1} \mathrm{H}$ NMR spectrum $\left(400 \mathrm{MHz}, \mathrm{CDCl}_{3}\right)$ of the new compound 2.

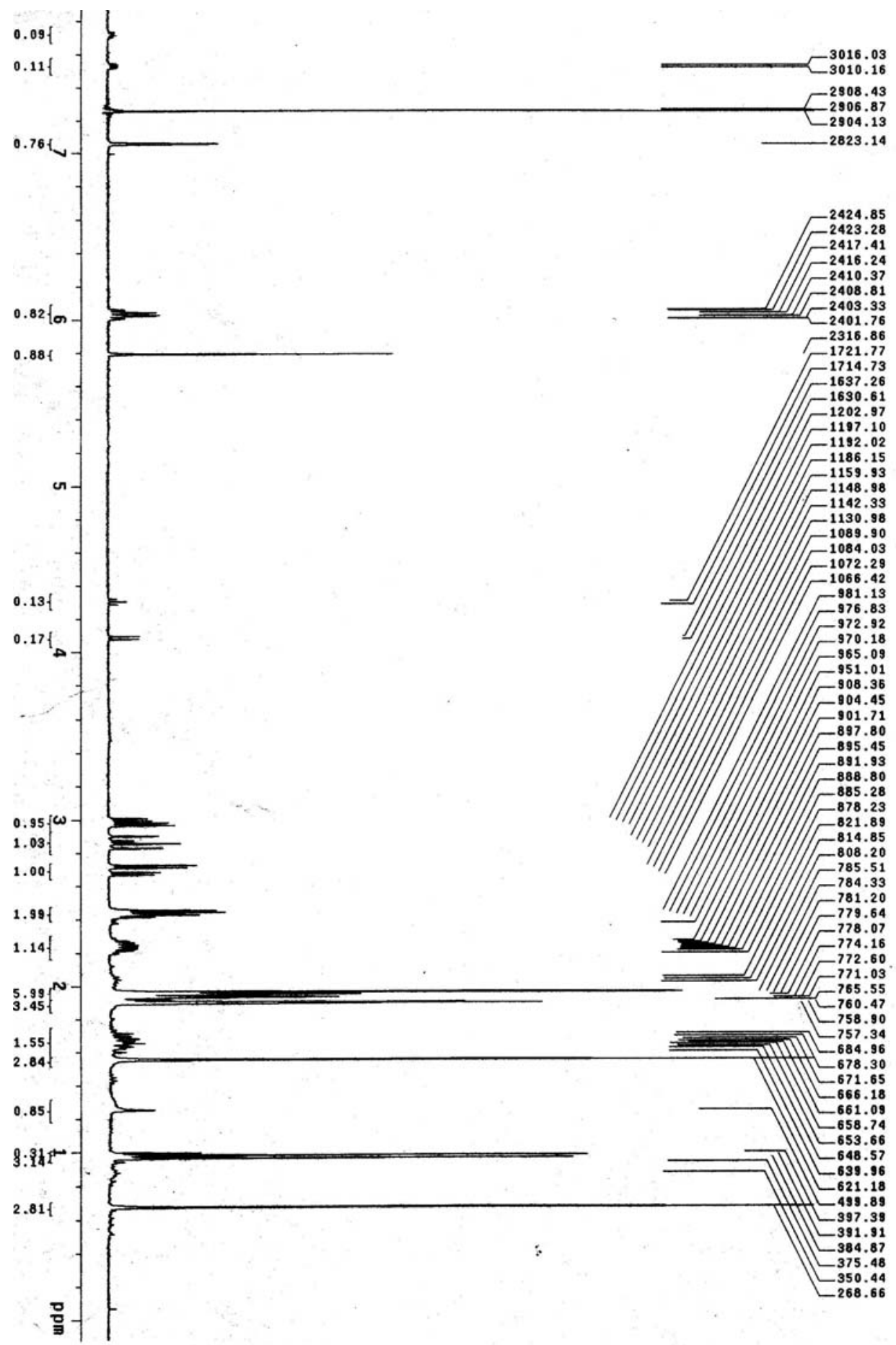


S6. ${ }^{13} \mathrm{C}$ NMR spectrum $\left(100 \mathrm{MHz}, \mathrm{CDCl}_{3}\right)$ of the new compound 2.

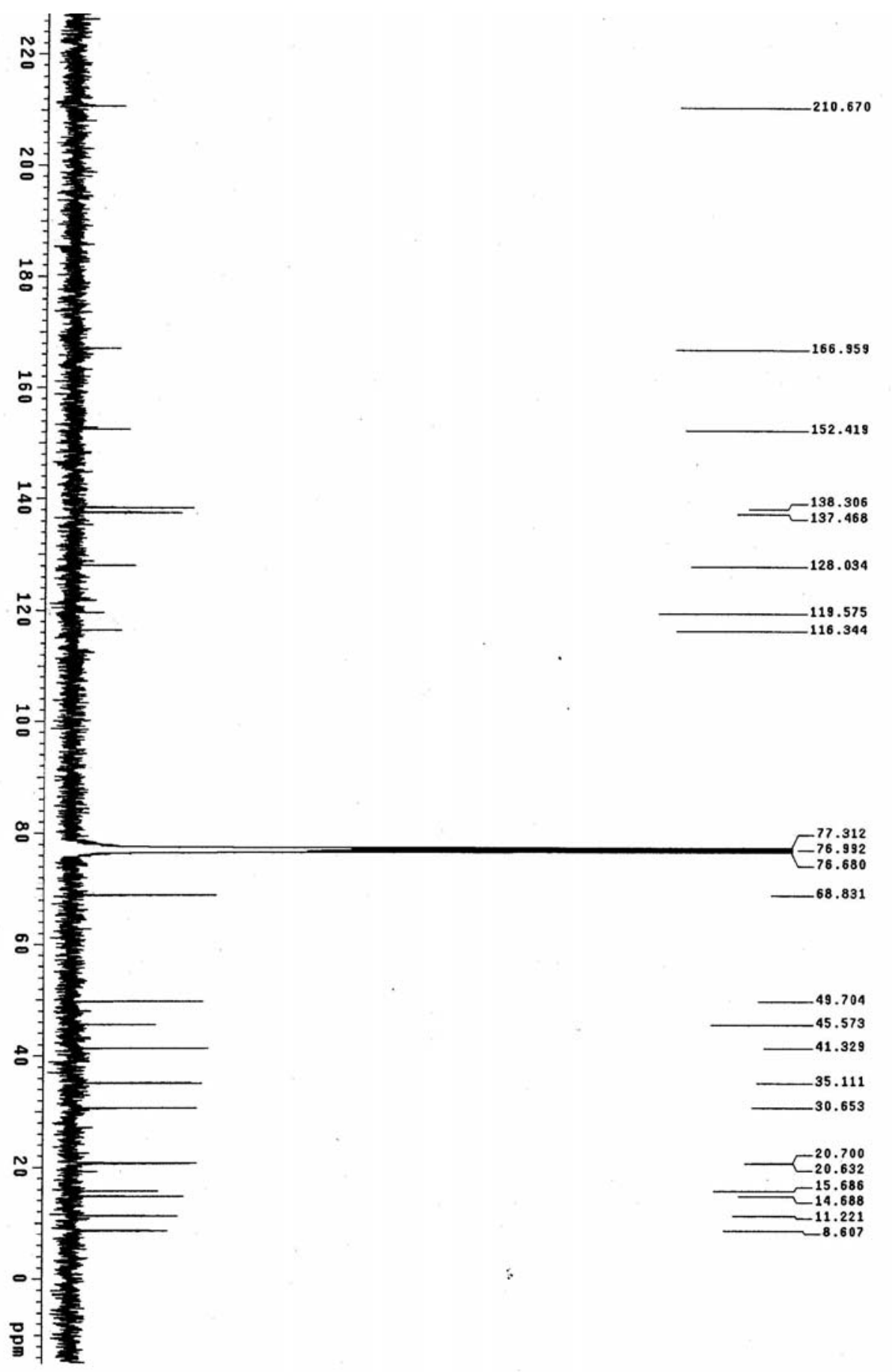


S7. ROESY spectrum of the new compound 2.

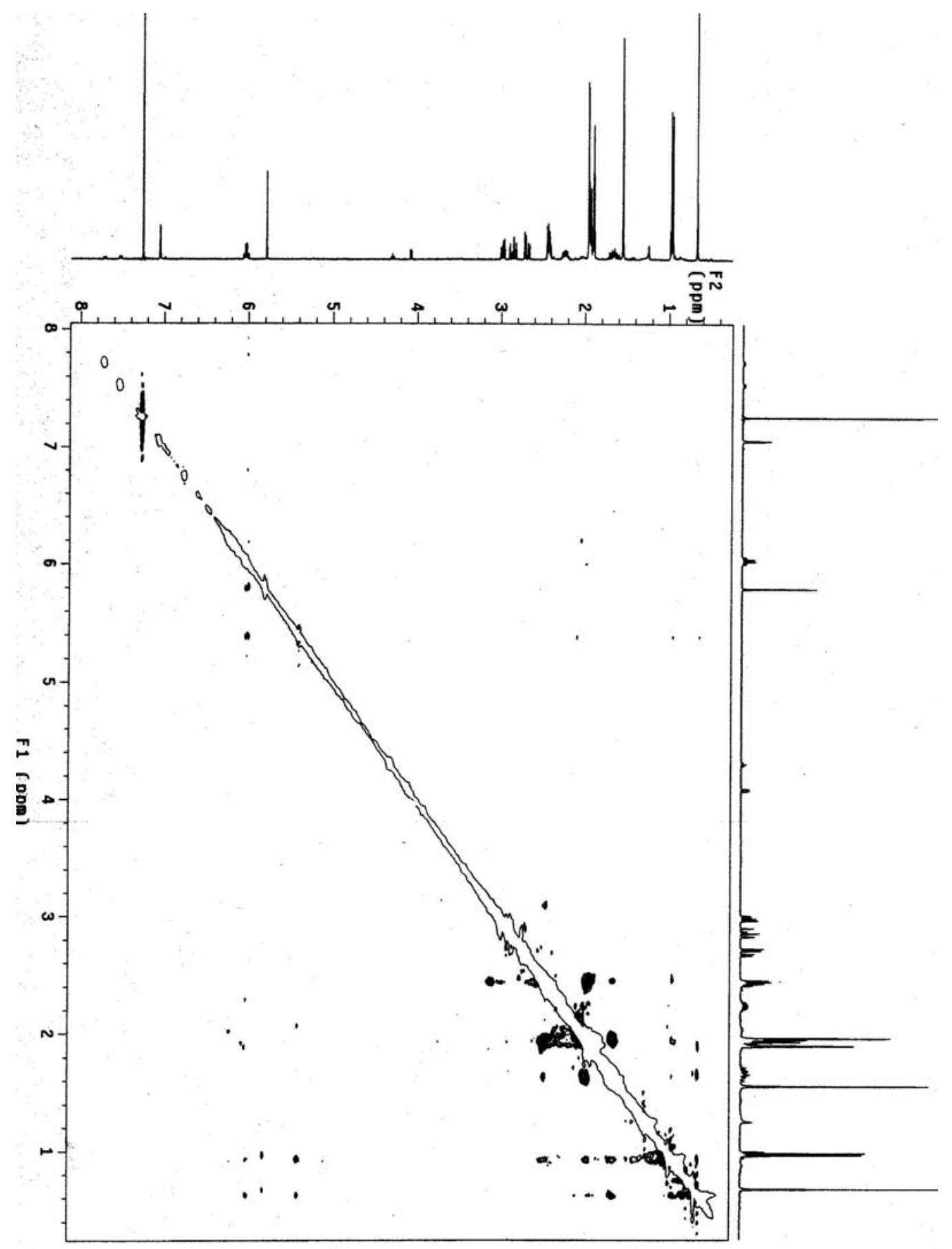


S8. ${ }^{1} \mathrm{H}$ NMR spectrum $\left(400 \mathrm{MHz}, \mathrm{CDCl}_{3}\right)$ of the new compound 3 .

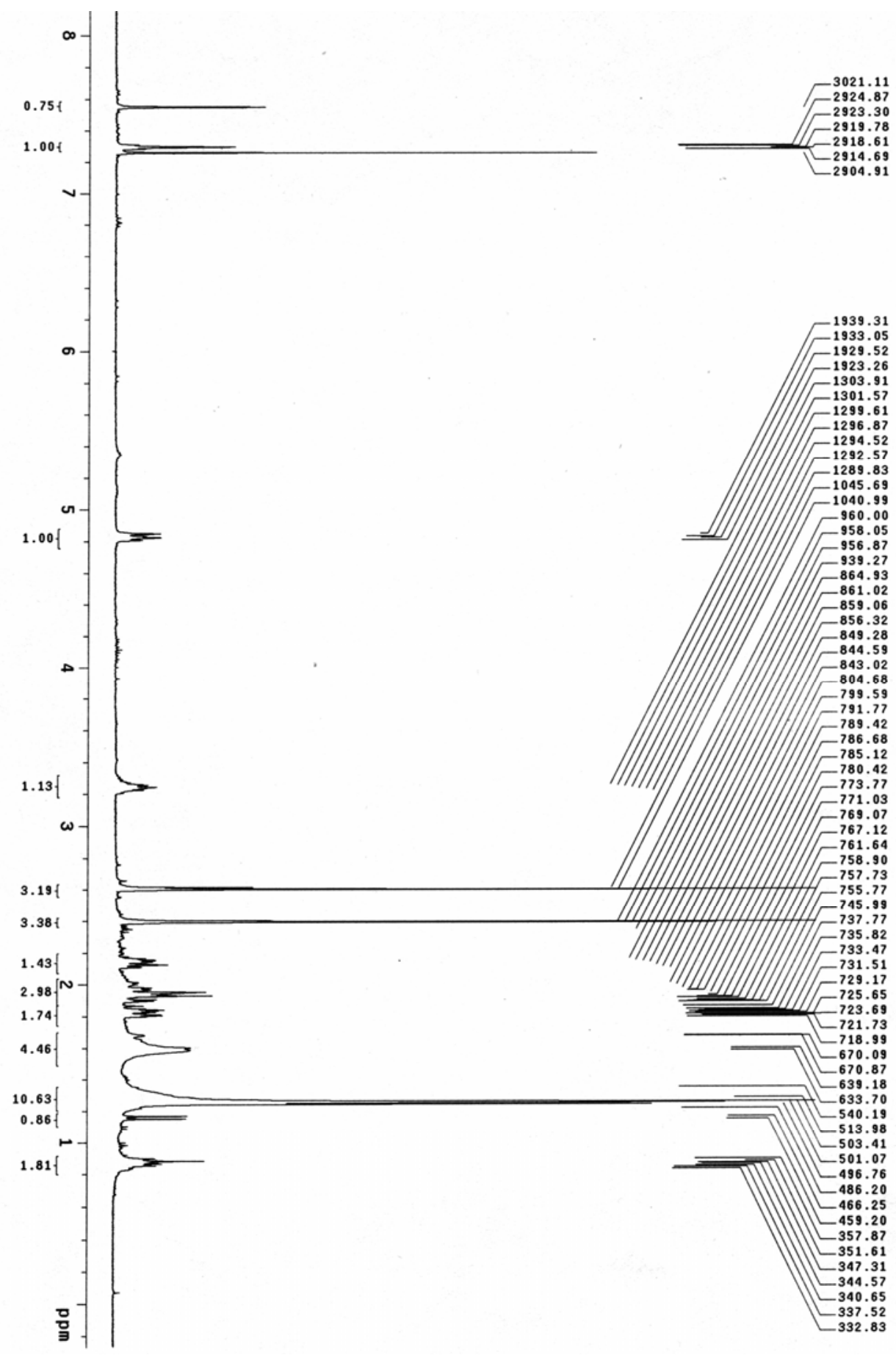


S9. ${ }^{13} \mathrm{C}$ NMR spectrum $\left(100 \mathrm{MHz}, \mathrm{CDCl}_{3}\right)$ of the new compound 3.

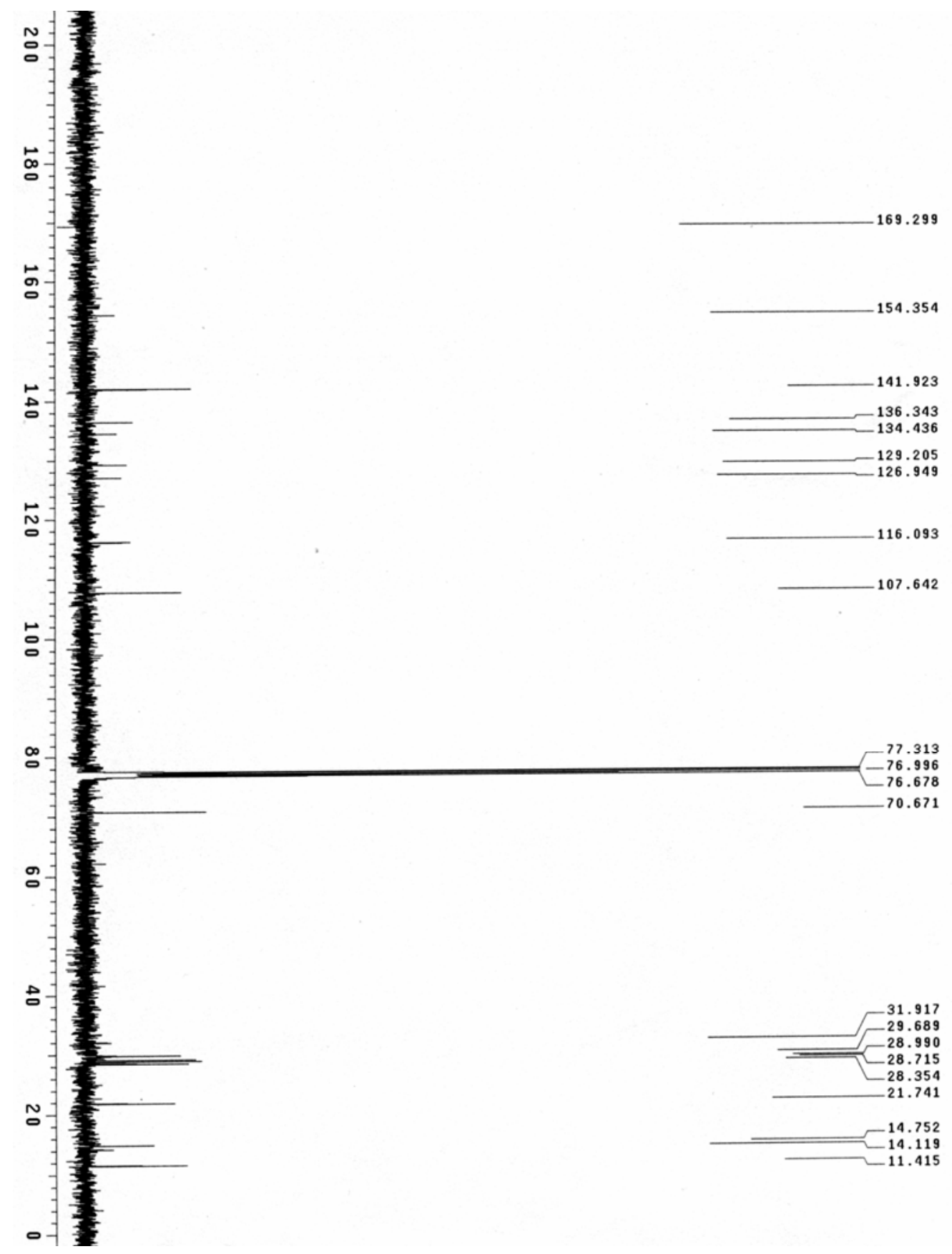


S10. HMBC spectrum of the new compound 3.

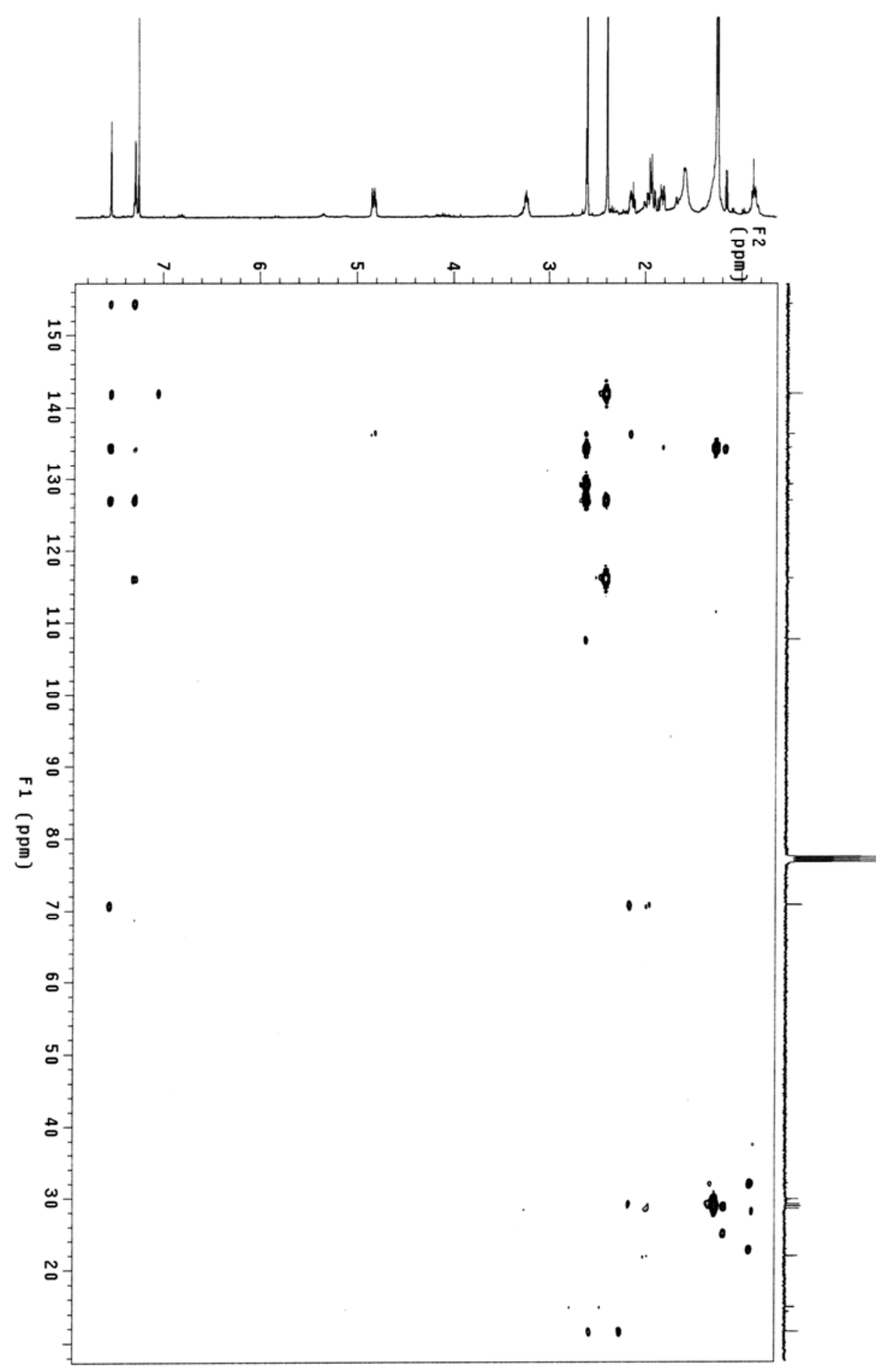


S11. ${ }^{1} \mathrm{H}$ NMR spectrum $\left(400 \mathrm{MHz}, \mathrm{CDCl}_{3}\right)$ of the new compound 4.

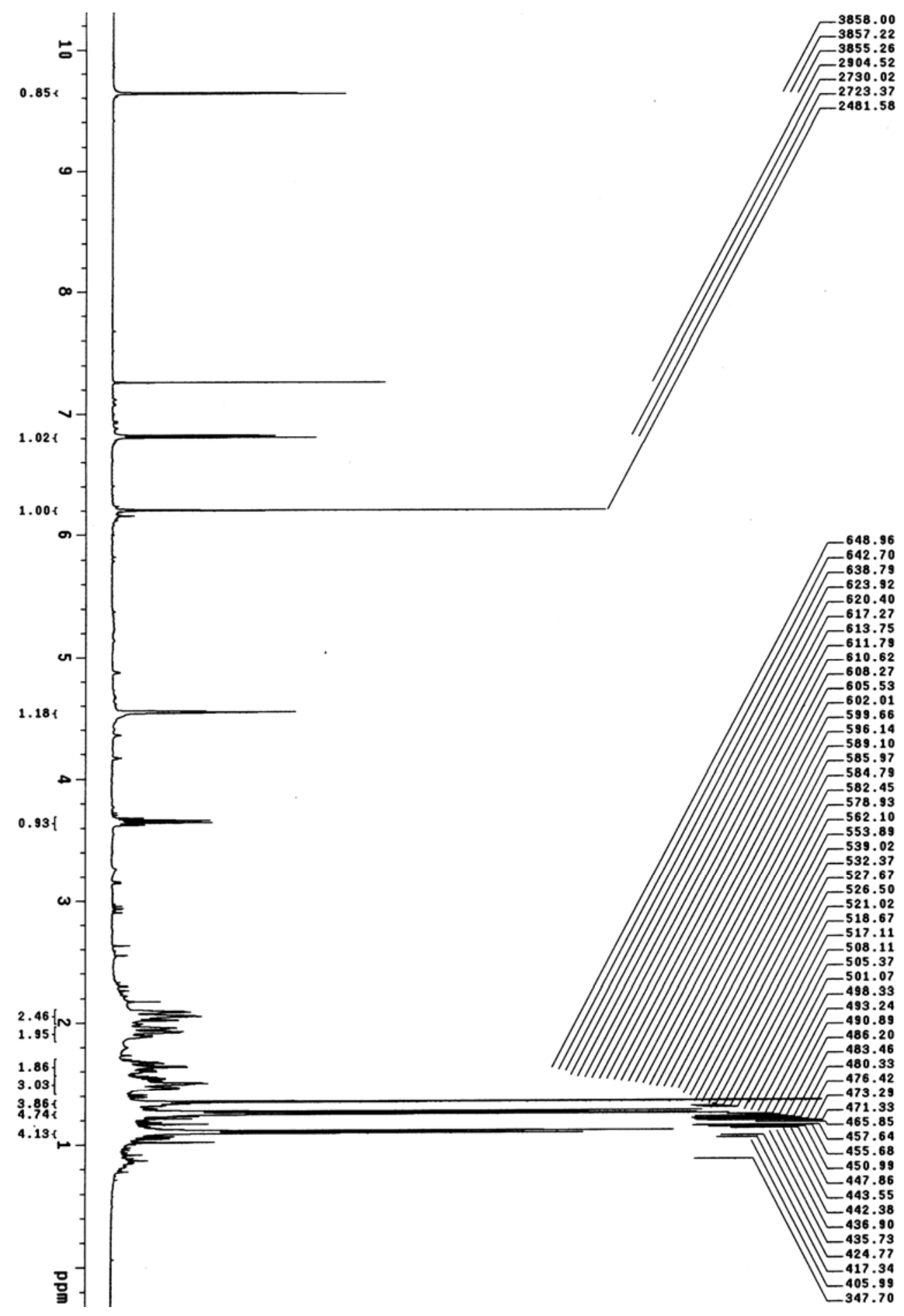


S12. ${ }^{13} \mathrm{C}$ NMR spectrum $\left(100 \mathrm{MHz}, \mathrm{CDCl}_{3}\right)$ of the new compound 4.

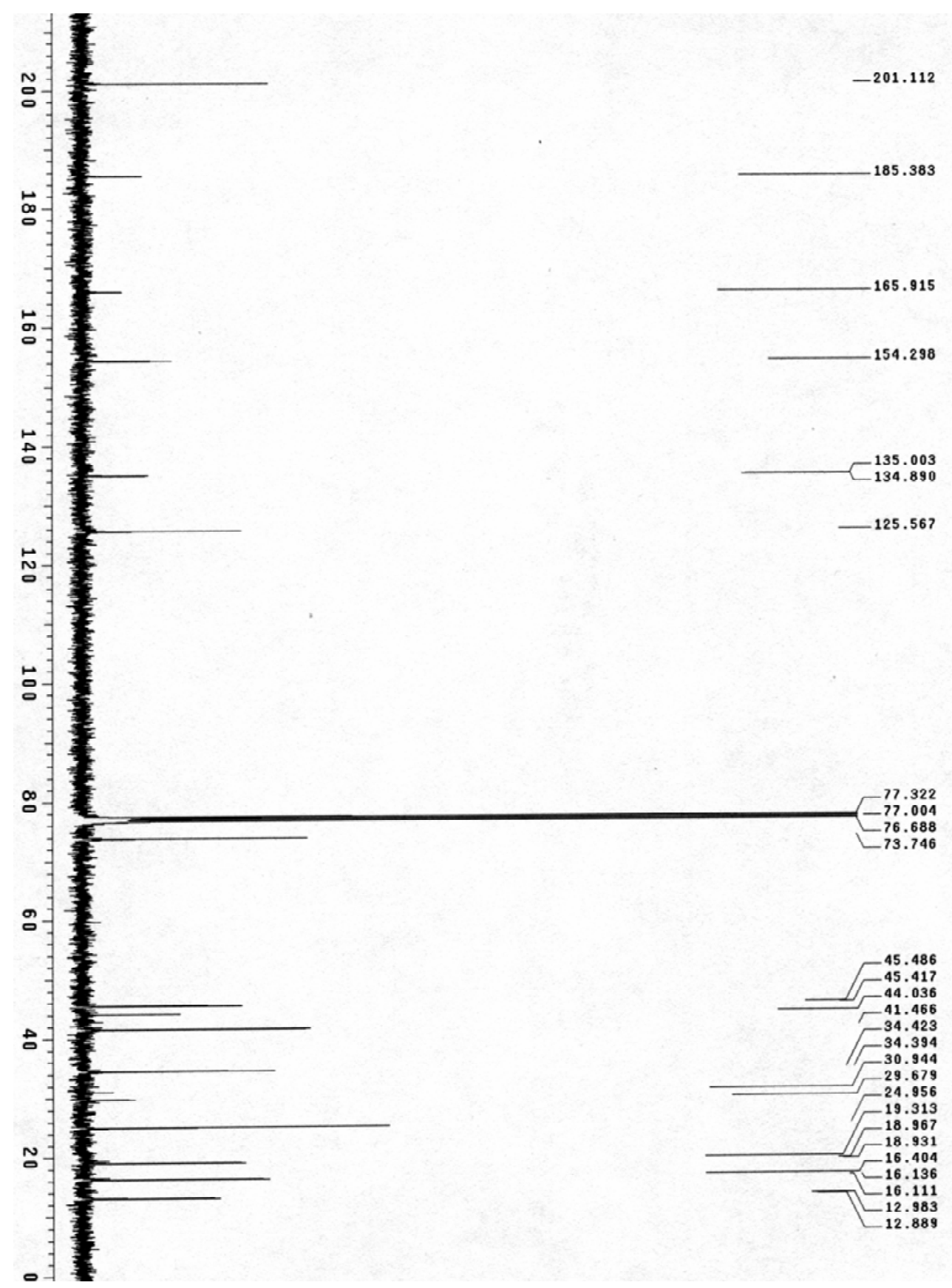


S13. HMBC spectrum of the new compound 4.

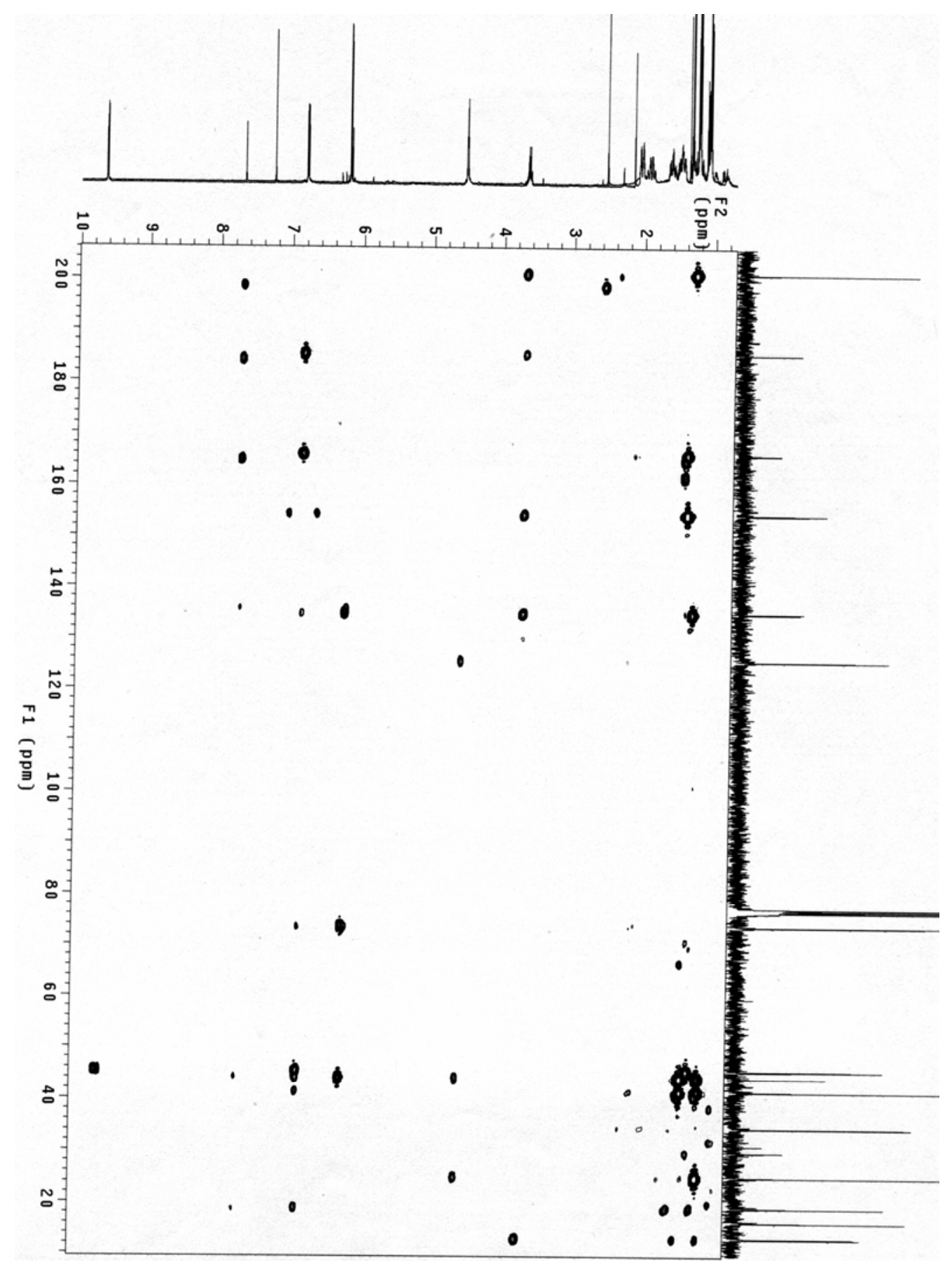


S14. ROESY spectrum of the new compound 4.

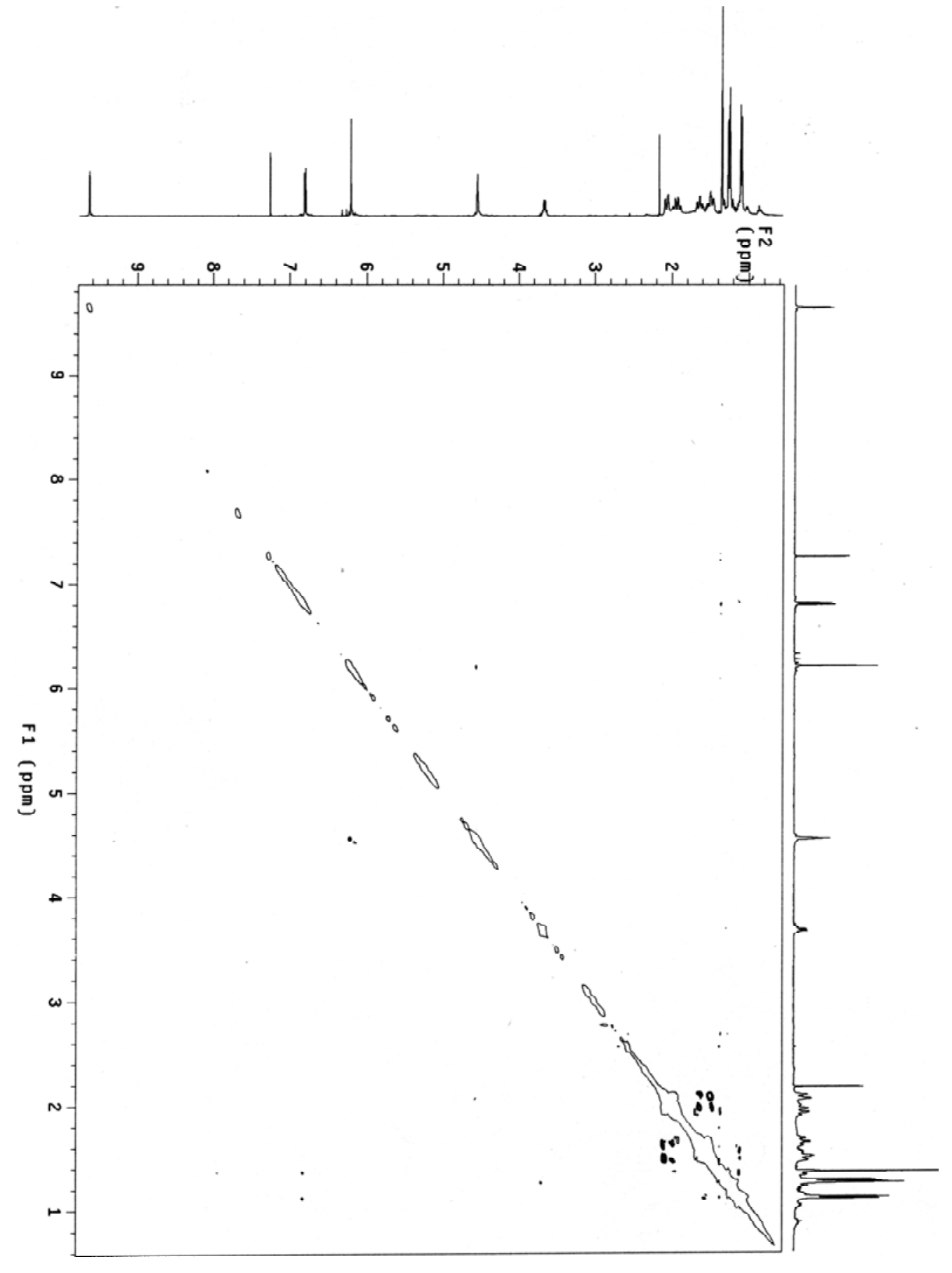

